\title{
Exposure to Scientific Explanations for Gender Differences Influences Individuals' Personal Theories of Gender and Their Evaluations of a Discriminatory Situation
}

\author{
Amanda Klysing ${ }^{1}$ \\ Published online: 3 June 2019 \\ (C) The Author(s) 2019
}

\begin{abstract}
Gender lay theory is a framework of information interpretation related to gender categorisation and can be divided into two general forms: gender essentialism versus gender as socially constructed. The present study investigated how exposure to scientifically framed explanations for gender differences affects individuals' gender lay theory and if endorsement of an essentialist gender lay theory influences discrimination attribution. The 413 Swedish participants were exposed to scientific explanations of gender differences, with either a biological or a social constructionist perspective, or to no-explanation control. Compared to the control condition, the social constructionist condition showed higher endorsement of a non-essentialist gender lay theory. The biological condition did not differ from the control condition, indicating that an essentialist view of gender might be the prevailing norm in Sweden. Discrimination attribution was indirectly affected by exposure to social constructionist explanations of gender differences through increasing endorsement of a non-essentialist gender lay theory, which predicted a higher degree of discrimination attribution. In other words, exposure to social constructionist explanations of gender differences predicted a greater recognition of discriminatory behaviour as such than did exposure to biological explanations or no explanation. Implications of the current study include the potential for social constructionist theories of gender to be used for educational purposes to increase recognition of discriminatory behaviour.
\end{abstract}

Keywords Essentialism · Gender discrimination · Gender differences · Discrimination attribution · Scientific communication . Sweden

Gender is recognised as a primary dimension in social categorisation (Kang and Bodenhausen 2015), and individuals in most cultures are sorted into the categories of female or male from birth based on physiological expressions (Blackless et al. 2000). These categories are then treated as corresponding to those of women and men (Ansara and Hegarty 2014). This view of gender as a binary phenotypic expression of an underlying genotype makes biology especial-

Electronic supplementary material The online version of this article (https://doi.org/10.1007/s11199-019-01060-w) contains supplementary material, which is available to authorized users.

Amanda Klysing

amanda.klysing@psy.lu.se

1 Department of Psychology, Lund University, Box 213, 221 00 Lund, Sweden ly salient in regard to distinctions between gender category members, and is related to perceiving gender as rooted in a biological essence (Brescoll et al. 2013). The common view of gender as biological furthermore uses reproductive roles as the basis for the division of humans into two genders (woman/ man), which are conceived of as each other's complements (Kay et al. 2007; Morgan and Davis-Delano 2016). A binary view of gender such as I described does not include a notion of genders other than women and men, which contributes to the exclusion and stigma experienced by individuals with nonbinary or other gender identities (Hegarty et al. 2018).

Influential theories of gender and gender differences in psychology are today frequently based on a sociobiological framework, where gender is viewed as a fundamentally biological categorisation which is further influenced by social processes (Buss 1995; Wood and Eagly 2012). This sociobiological view of gender has been criticized for promoting gender essentialism through treating biology as a pre-discursive 
gender essence (Butler 2006) as well as containing fundamental ontological and methodological flaws in its scientific support (Meynell 2012), continuing harmful "corrective" practices toward intersex individuals (Blackless et al. 2000) and cementing gender status inequalities (Stone 2004). In contrast, a social constructionist theory views gender not as an internal quality, but rather as a social categorisation which performs a hierarchical, organising function of individuals in society: Gender is treated as a structure of signification, thus acknowledging it both as a macro-structure and as being perpetuated by performances of gendered practices (Connell 1987, p. 2638). Biological categorisation is not viewed as an objective foundation of gender, but rather as something that must be interpreted within a socially constructed system of meaning in order to be understood (Connell 1995, pp. 61-65).

How do different theories regarding gender influence lay peoples' conceptualisation of gender as a social category and what are the consequences of considering gender as based on a common essence or as socially constructed? The current study seeks to provide input on these questions by studying how individuals' conceptualisation of gender categorisation is influenced by reading different scientific explanations for gender differences. Furthermore, the current study investigates the impact of individuals' gender lay theory on propensity to attribute discrimination in response to a situation of gender discrimination. Additionally, the current research is the first known of its kind to be conducted in a Sweden context, which is ranked as one of the most gender equal countries in the world by the Global Gender Gap Index (World Economic Forum 2018). As of 2017, Sweden also extended its antidiscrimination law to include seven grounds for discrimination (gender, transgender identity or expression, ethnicity, religion or other belief, disability, sexual orientation, and age) and added demands for employers to work proactively to counteract direct and indirect discrimination in the workplace (Discrimination Act 2008:567).

\section{Psychological Essentialism}

Essentialist and social constructionist theories of causes for gender differences dovetails a division found in people's personal theorizing regarding social categories, where categories are seen as either based on a shared essence or as human artefacts (Rothbart and Taylor 1992). Lay peoples' theories about social categories have been studied under the framework of implicit person theories (also known as lay person theories), which are defined as frameworks for interpretation of information guiding an individual's response to said information (Dweck et al. 1995; Plaks 2017). One specific implicit person theory that is used to explain causes of group differences and set criteria for group categorisation is psychological essentialism (Haslam et al. 2000; Martin and Parker 1995;
Medin and Ortony 1989). Psychological essentialism refers to the tendency of individuals to infer that members of a social category share an underlying essence that motivates their inclusion into that category, regardless of whether any such defining essence exists (Medin and Ortony 1989). What a specific essence consists of is often unknown, in which case individuals make use of an "essence placeholder" (Medin and Ortony 1989, p. 184); genetics commonly occupy this position in regard to social categories (Keller 2005). This reliance on genetics and genetic correlates is evident both throughout psychological research and among lay people (Hyde et al. 2018), making the notion of gender as a biological category intimately connected to psychological essentialism.

Haslam and colleagues (Haslam et al. 2000) identified two distinct dimensions within psychological essentialism: natural kinds and entitativity. The dimension natural kinds refers to the extent to which a category is seen as natural, discrete, immutable, and historically persisting. The dimension entitativity refers to the extent to which a category is perceived as informative, homogenous, grounded in inherent properties, and determinative of identity. Social categories vary in the degree to which they are seen as natural and/or entitative, and the combination of the two dimensions has been shown to be connected to social status (Haslam et al. 2000). Categories which are perceived as natural and entitative (e.g., women) are rated as having lower social status than those seen as natural kinds but not entitative (e.g., men) who are seen as having higher social status (Haslam et al. 2000). This connection between social status and psychological essentialism could be a reason for essentialist beliefs regarding social categories to be associated with stereotype endorsement (Yzerbyt et al. 1998; Yzerbyt et al. 2001), self-stereotyping (Coleman and Hong 2008), and higher levels of prejudice toward immigrants and ethnic outgroups (Andreychik and Gill 2015; Bastian and Haslam 2008; Keller 2005; Rangel and Keller 2011).

Peoples' endorsement of essentialist or non-essentialist gender theories has also been manipulated in previous studies by exposing participants to faux scientific articles advocating for either biological or social explanations for gender differences. These manipulations make use of the fact that although there is a conception that gender category essences are based in biology or genetics, a majority of individuals do not have extensive knowledge of these topics. Therefore, the actual content of the proposed category's essence comes from interpretation of information from sources which are deemed to be reliable, such as members of the scientific community (Gelman et al. 1986; Racine et al. 2005). Studies in which gender lay theory has been manipulated through use of scientific articles show that higher endorsement of an essentialist gender lay theory increases men's endorsement of gender discriminatory practices (Morton et al. 2009), predicts higher justification of the current gender system (Kray et al. 2017) 
and increases gender stereotype endorsement (Brescoll and LaFrance 2004).

However, the perceived essence of an essentialised group may also be a non-biological factor, and both genetic and social determinism have been identified as potential underlying factors of essentialist thinking regarding social groups (Rangel and Keller 2011). This pattern suggests that determinism, rather than content of perceived essence, is what underlies essentialist thinking. Previous studies using a text manipulation to influence gender lay theory have contrasted biological explanations for gender differences with sociocultural explanations and have not addressed the factor of social determinism (Brescoll and LaFrance 2004; Coleman and Hong 2008; Morton et al. 2009). The present research adds to the previous literature by investigating the impact of social constructionist explanations for gender differences on gender lay theory.

\section{Discrimination Attribution}

Endorsement of an essentialist gender lay theory has been found to influence degree of discrimination attribution by increasing men's endorsement of discriminatory practices toward women (Morton et al. 2009) and by decreasing participants' attribution of discrimination as a cause for women's underrepresentation in occupations and leadership roles within science, technology, engineering, and mathematics (STEM; Cundiff and Vescio 2016). The connection between essentialism and degree of discrimination attribution has been suggested to be a result of essentialism portraying unjust treatment as an inevitable result of membership in the essentialised group rather than unfair treatment, which in turn protects the individual's view of society as a meritocracy (Brescoll et al. 2013). According to system justification theory, to the extent that people have a need to see the current social system as a meritocracy, they are also more motivated to defend the current status quo (Jost et al. 2004). This defence is conducted through the use of stereotypes to legitimise status differences and make inequality seem natural and appropriate (Jost et al. 2004). Lack of discrimination attribution in response to a discriminatory situation can be seen then as a form of system justification (Kaiser et al. 2006) because discriminatory actions are a violation of meritocracy principles by using a person's group membership as the basis of action rather than the person's merits. In contrast to the previously mentioned studies that have investigated discrimination attribution in general terms, the current study utilises a vignette design. This approach allows for an investigation into how gender essentialist reasoning impacts discrimination attribution in response to a specific situation of gender discrimination.

\section{Aims and Hypotheses}

The primary objectives of the present study are to empirically investigate to what extent scientifically framed information regarding gender differences between women and men can influence individuals' gender lay theory and to explore if gender essentialism serves a system justification purpose by decreasing discrimination attribution. The current study complements previous research on the topic by contrasting a biological framework with a social constructionist framework in order to decrease the influence of social determinism and by using a vignette design to investigate how gender essentialist reasoning impacts discrimination attribution in response to a specific rather than general situation of gender discrimination.

In relation to the stated aims, I propose the following hypotheses. First, exposure to biological explanations for gender differences, compared to a no exposure control, will lead to greater support for an essentialist lay theory of gender (Hypothesis 1a) and exposure to social constructionist explanations of gender differences, compared to the control, will lead to greater support for a non-essentialist lay theory of gender (Hypothesis 1b). Second, exposure to scientific explanations of gender differences will have an indirect effect on discrimination attribution through gender lay theory. Specifically, exposure to biological explanations, compared to a no exposure control, will decrease discrimination attribution mediated by greater endorsement of an essentialist gender lay theory (Hypothesis 2a) and exposure to social constructionist explanations of gender differences, compared to the control, will increase discrimination attribution mediated by greater endorsement of a non-essentialist gender lay theory (Hypothesis 2b).

\section{Method}

\section{Participants}

The experiment was conducted through an online survey using Qualtrics (www.qualtrics.com). Participants were recruited using advertising in various groups on the social media site Facebook (i.e., in groups consisting of lay people with scientific interest, groups focused on specific hobbies, and groups intended for social interaction); the only condition for inclusion was fluency in Swedish. The sample consisted of 413 participants between 17 and 75 years of age $(M=41.1, S D=11.97)$ who were randomly allocated to biological $(n=133)$, social constructionist $(n=125$,$) or control (n=155)$ conditions. Participants provided information regarding their gender identity as free-text responses in order to avoid cisgenderism following the recommendations of Ansara and Hegarty (2014). Nineteen participants did not 
indicate a gender, 275 identified as women, 111 as men, and 8 as having a varying or non-binary gender identity. Given the small number of non-binary participants, they were excluded from gender-based analyses for statistical reasons.

\section{Materials}

\section{Manipulated Texts}

Manipulated texts were described to participants as an excerpt from a scientific publication that investigated reasons for gender differences in predispositions and behaviour. This method of manipulation has been used successfully in previous studies to induce differences in essentialist mind-set (e.g., Coleman and Hong 2008; Hong et al. 2004; Morton et al. 2009). The biologically focused article described the results of a longitudinal study that supposedly supported the notion that behavioural and predispositional gender differences are unavoidable due to their basis in biological differences. For example, the article claimed that "the results from this study make clear that masculine and feminine qualities, as well as gender differences regarding these, are largely connected to biology and are resistant to change." The social constructionist article instead described gender differences in behaviour and predispositions as inexplicable by biology alone and instead portrayed them as based in the social organisation of reproductive roles combined with socialisation practices. Manipulated texts were of moderately high language difficulty, mimicking the language structure of published popular scientific articles. In order to ensure participants' concentration, texts were kept short, with article length ranging from 200 to 341 words. (The full texts, both in the original Swedish and translated English, can be found in the online supplement.) Agreement with both texts' arguments was measured on a scale from 1 (do not agree at all) to 5 (completely agree) and showed acceptably normal distributions, suggesting that social desirability effects were minimal.

\section{Discrimination Vignettes}

Two vignettes describing instances of gender-based workplace discrimination were designed using the definition of gender-based discrimination given by the Swedish Equality Ombudsman (see http://www.do.se/other-languages/english/ what-is-discrimination/ for more information). The vignettes describe two different situations in which a woman was bypassed for promotion by her boss in favour of a male colleague: in the first instance for being a mother and in the second instance as a result of being excluded from a male homosocial environment. (The complete vignettes, in both the original Swedish and translated to English, can be found in the online supplement.)

\section{Pilot Testing}

Different versions of both manipulated texts and discrimination vignettes were pilot tested before the final versions were selected to ensure that the manipulated texts were believable as scientific articles and that the discrimination vignettes were seen as ambiguous situations. The pilot study was an online questionnaire distributed through Facebook groups that gather potential participants for responding to psychological surveys. Participants $(n=38)$ were randomly assigned to read one of four manipulated texts designed to describe four different scientific viewpoints regarding the causes of gender differences in behaviours and characteristics. The four texts were varied along the dimension of exclusivity of cause of gender differences: Gender differences were described as being exclusively biologically caused, primarily biologically caused, exclusively socially caused, and primarily socially caused. Participants then indicated the extent to which they agreed with the text on a scale from 1 (do not agree at all) to 5 (completely agree), completed the Gender Theory Questionnaire (described in the following), and were given the chance to comment in free-text on the materials they had read.

No participants expressed a disbelief in the authenticity of the texts as scientific material in their free-text comments. Due to the small number of participants in each condition, visual inspection of mean values rather than significance testing was conducted. The text featuring primarily social constructionist arguments showed the highest difference in gender theory scores and text agreement closer to the midpoint of the scale than for the exclusively social constructionist article, indicating less of a concern with social desirability, and was chosen as stimuli material. The text featuring primarily biological arguments was chosen to balance the level of argument of the social constructionist article because the difference in gender theory scores and text agreement was minimal between the two biological texts (see Table 1).

Following exposure to the manipulated texts, participants read five vignettes designed to comply with examples of gender based discrimination given by the Swedish Equality Ombudsman. The vignettes were randomly presented, and participants completed a measure of discrimination attribution for each vignette (see the following for a description of measure). Given that previous research has shown that ambiguous situations offer the greatest potential for judgements to be influenced by individual factors because no strong social norm is present to guide attribution (Gaertner and Dovidio 2005; Snyder 1983), those vignettes showing the highest degree in ambiguity in ratings were selected. The vignettes that showed the highest degree of ambiguity in ratings, as defined by being closest to the midpoint of the discrimination scale and having the highest variance in ratings, were a vignette describing exclusion from a homosocial environment $\left(M_{\text {discrimination }}=7.08, S D=2.39\right)$ and another vignette 
Table 1 Descriptive data by experimental condition for lay gender theory and text agreement

\begin{tabular}{|c|c|c|c|c|c|c|c|c|}
\hline \multirow[b]{2}{*}{ Dependent measure } & \multicolumn{2}{|c|}{$\begin{array}{l}\text { Exclusively } \\
\text { biological }\end{array}$} & \multicolumn{2}{|c|}{$\begin{array}{l}\text { Primarily } \\
\text { biological }\end{array}$} & \multicolumn{2}{|c|}{$\begin{array}{l}\text { Exclusively } \\
\text { social }\end{array}$} & \multicolumn{2}{|c|}{$\begin{array}{l}\text { Primarily } \\
\text { social }\end{array}$} \\
\hline & $M$ & $S D$ & $M$ & $S D$ & $M$ & $S D$ & $M$ & $S D$ \\
\hline Social gender theory & 4.30 & 1.18 & 4.26 & 1.15 & 4.11 & 1.75 & 4.89 & 1.10 \\
\hline Biological gender theory & 2.24 & 1.17 & 2.50 & 1.06 & 2.18 & 1.38 & 2.11 & .75 \\
\hline Text agreement & 2.22 & 1.09 & 2.00 & 1.16 & 3.73 & 1.10 & 3.29 & 1.25 \\
\hline$n$ & 10 & & 10 & & 11 & & 7 & \\
\hline
\end{tabular}

Gender theory was measured on a 6-point scale on which higher numbers indicate greater endorsement of respective theory. Text agreement was measured on a 5-point scale on which higher numbers indicate greater agreement with the text describing discrimination due to motherhood $\left(M_{\text {discrimination }}=\right.$ $7.88, S D=1.89)$. The other vignettes tested described sexist comments from a manager in task assignment $\left(M_{\text {discrimination }}=\right.$ $8.48, S D=1.05)$, introduction of a gender specific dress code $\left(M_{\text {discrimination }}=7.95, S D=1.60\right)$, and non-elongation of employment due to pregnancy $\left(M_{\text {discrimination }}=8.08, S D=1.65\right)$.

\section{Procedure and Measures}

Participants were randomly assigned to read one of two manipulated texts (biological or social constructionist) or no text (control) and subsequently completed the Gender Theory Questionnaire. Next, participants read the two vignettes describing an ambiguous instance of gender discrimination in the workplace and rated the extent to which they found the situations discriminatory. Participants were then asked to indicate their gender identity and responded to the Modern Sexism Scale. They also provided their age and political orientation $(1=$ far to the left to $7=$ far to the right). Given that engagement with gender issues in general has been found to be an important variable regarding perception of gendered language (Gustafsson Sendén et al. 2015; Lindqvist et al. 2016), participants' interest in gender issues was also measured from 1 (not interested at all) to 5 (very interested). Lastly, the remaining demographic questions followed along with a debriefing check asking participants to write what they thought the purpose of the study was.

The present study was carried out in accordance with the Swedish national guidelines on ethical research (Swedish Research Council 2017). This means that participants were informed that their participation was voluntary and anonymous and that no personal information would be collected. Following completion of the study participants were debriefed and informed that the text they had read had been constructed by the researcher to resemble a popular scientific article rather than being an actual excerpt. The present study did not entail any handling of personal data.

\section{Gender Theory Questionnaire}

The Gender Theory Questionnaire developed by Coleman and Hong (2008) was used to measure gender lay theory. The Gender Theory Questionnaire consists of two subscales with five items each: one subscale measures endorsement of a biological theory of gender (e.g., "When men and women differ in some way, it is likely that the difference is due to biological factors") and the other subscale measures endorsement of a social theory of gender (e.g., "The properties of gender are constructed totally for economic, political, and social reasons"). For the purposes of the present study, an item directly measuring perceived immutability of gender as viewed in an essentialist lay theory of gender ("Gender category membership is set from birth and cannot be changed") was added to the biological theory of gender subscale. Participants rated their agreement with each statement on a 6-point Likert scale from 1 (do not agree at all) to 6 (completely agree). Items of the Gender Theory Questionnaire were translated into Swedish; backtranslation was performed by a bilingual colleague and showed satisfactory validity of translation. Given that the social gender lay theory scale and the biological gender lay theory scale correlated strongly $(r=-.72)$, they were combined in order to allow for joint analysis of gender lay theory endorsement in a single regression model. The combined gender theory scale ( $\alpha=.88$ ) was created by reverse scoring items on the biological gender lay theory scale and calculating a mean score of all gender lay theory items $(M=3.85, S D=1.04)$. A high score thus indicates a higher endorsement of a non-essentialist gender lay theory whereas a low score indicates a higher endorsement of an essentialist gender lay theory.

\section{Attributions to Gender Discrimination}

The degree of attribution to gender discrimination regarding the vignettes was measured with three items: "To what extent to you think that the boss' behaviour was justified," "To what extent do you think that the boss' behaviour was discriminatory?" and "To what extent to you think that the 
fact that the employee was a woman influenced the boss' behaviour?," each rated on a 9-point Likert scale from 1 (not at all) to 9 (to a great extent). Items for attribution of gender discrimination were chosen based on the criteria for discrimination established by Major et al. (2002), who define discrimination attribution as a judgement that treatment of a person is based on their membership in a social group and that the treatment is unjust. Following reverse scoring of the rating of the extent to which the behaviour was justified, these three items were averaged to form a single index of discrimination endorsement. Discrimination attribution in response to the two vignettes showed high internal reliability when collapsed into a single scale $(\alpha=.81)$.

\section{Modern Sexism}

A translated seven-item version of the Modern Sexism Scale (Ekehammar et al. 2000) was used as an indicator of support for the gender inequality status quo $(\alpha=.80)$. The scale was modified to not rely on a binary perception of gender by altering items like "Discrimination toward women is no longer a problem in Sweden" to "Discrimination due to gender is no longer a problem in Sweden." Participants rated the statements on a scale from 1 (do not agree at all) to 5 (completely agree).

\section{Results}

To ensure that there were no significant differences among the three study groups (biological, social constructionist, and control) regarding measured background factors, a MANOVA was performed with age, modern sexism, political orientation, and interest in gender issues as dependent variables and condition as the between-group factor. No significant group level differences were found for political orientation, $F(2,387)=$ $1.77, p=.17$, interest in gender issues, $F(2,387)=2.42$, $p=.09$, or modern sexism, $F(2,387)=1.20, p=.30$. There was, however, a significant difference in age among the randomly assigned conditions, $F(2,387)=11.19, p<.001$, $\eta_{\mathrm{p}}{ }^{2}=.06$. Pairwise comparisons with Tukey HSD correction showed that the control group $(M=44.50, S D=11.43)$ was significantly older than participants in both the biological $(\mathrm{M}=38.65, S D=12.26, p<.001, d=.50)$ and the social constructionist $(M=38.94, S D=11.08, p<.001, d=.49)$, conditions. In order to minimize the risk of confounding age with condition, age was included as a covariate in all analyses that included the experimental groups.

Correlations between all continuous and dichotomous variables were examined (see Table 2). Regarding correlations with the two variables of main interest - gender theory and discrimination attribution - significant correlations are found with all remaining variables (with the exception of age, which did not correlate with discrimination attribution). In order to isolate the effect of exposure to differing explanations for gender differences in the subsequent regression analyses, all variables with significant correlations to the analysis' dependent variable were included as covariates. Because there is a high degree of intercorrelation among study variables, variance inflation factors (VIFs) were calculated and reported along with regression coefficients.

To test Hypothesis 1, that exposure to a certain explanation for gender differences would lead to differing endorsement of gender lay theories, I performed a three-stage hierarchical multiple regression with a combination of the social gender lay theory scale and the biological gender lay theory scale as the dependent variable. Due to the difference in age between the control group and the experimental groups, age was controlled for in Step 1 along with the additional covariates of modern sexism, political orientation, and interest in gender issues. Gender identity $(0=$ woman, $1=$ man $)$ and condition (dummy coded with the control condition as reference) was added in the second step. Because there has been mixed results regarding whether gender has a moderating effect on the relation between exposure to different explanations for gender
Table 2 Correlations among study variables

\begin{tabular}{|c|c|c|c|c|c|c|}
\hline \multirow[b]{2}{*}{ Variable } & \multicolumn{6}{|c|}{ Correlations } \\
\hline & 1. & 2. & 3. & 4. & 5. & 6. \\
\hline 1. Modern sexism & - & & & & & \\
\hline 2. Discrimination attribution & $-.59 * * *$ & - & & & & \\
\hline 3. Gender theory & $-.63 * * *$ & $.50 * * *$ & - & & & \\
\hline 4. Gender & $.29 * * *$ & $-.32 * * *$ & $-.19 * * *$ & - & & \\
\hline 5. Age & .06 & .06 & $-.16 * *$ & .04 & - & \\
\hline 6. Interest in gender issue & $-.49 * * *$ & $.29 * * *$ & $.44 * * *$ & $-.17 * *$ & $-.12 *$ & - \\
\hline 7. Political orientation & $.46^{* * *}$ & $-.19 * * *$ & $-.42 * * *$ & .05 & $.14^{* *}$ & $-.30 * * *$ \\
\hline
\end{tabular}

For the dichotomous variable Gender, the reported coefficients are point-biserial correlation coefficients, for remaining variables, reported values are Pearson's correlation coefficients

$* p<.05 . * * p<.01 . * * * p<.001$ 
differences and perceptions of gender differences (Morton et al. 2009; Kray et al. 2017), the interaction between gender and condition was added in Step 3. Due to the small number of interactions in this analysis, predictors where kept in unstandardized form following recommendation from Hayes (2013). Descriptive statistic for the dependent variables by condition can be found in Table 3 .

Regression statistics are displayed in Table 4. The strongest predictor was modern sexism, where stronger sexism was associated with higher endorsement of an essentialist gender theory. Remaining covariates were also significant predictors of gender lay theory: older age and stronger right-wing political orientation predicted a more essentialist gender lay theory whereas higher general interest in gender issues predicted a less essentialist gender lay theory. Participants' gender did not predict gender lay theory endorsement, neither on its own nor in interaction with experimental condition. Exposure to the social constructionist article, compared to the no exposure control, was still a significant predictor of gender lay theory when covariates were accounted for. The direction of this effect, as shown in Table 4, showed that exposure to the social constructionist article resulted in higher endorsement of a nonessentialist gender lay theory compared to the control group, supporting Hypothesis $1 \mathrm{~b}$. Contrary to Hypothesis 1a, exposure to the biological article did not lead to a difference in gender lay theory endorsement compared to the control group.

According to Hypothesis 2, exposure to different explanations for gender differences (biological/social constructionist) will have an indirect effect on discrimination attribution through gender lay theory. This indirect effect hypothesis was tested using the SPSS macro PROCESS, v. 2.16.3, Model 4 (Hayes 2013) where 95\% confidence intervals were calculated using a bias-corrected bootstrap approach with 10,000 bootstrap samples. A model was created to investigate the direct and indirect effects of experimental condition (dummy coded with control group as reference level) through gender lay theory. As in the previous regression analysis, age, modern sexism, participants' gender $(0=$ woman, $1=$ man $)$, political orientation, and interest in gender issues were added as covariates given their correlations with the mediator and outcome variables.

First, several covariates had direct effects on discrimination attribution: higher modern sexism strongly predicted lower discrimination attribution, whereas younger age and stronger leftwing political orientation to a lower degree predicted higher discrimination attribution. Participants' gender had no significant effect on discrimination attribution. There was a marginally significant omnibus direct effect of experimental condition on discrimination attribution, $F(2,360)=3.11, p=.05$. This overall effect was driven by the direct effect of the social constructionist condition which was weakly significant $(b=.40, S E=.19,95 \%$ CI $[.04, .77])$. There was no significant direct effect of the biological condition $(b=-.0030, S E=.18,95 \%$ CI $[-.36, .35])$. There was also an indirect effect of condition on discrimination attribution through gender lay theory $\left(b=.01, S E_{\text {boot }}=.004\right.$, $95 \%$ CI $[.001, .020])$. The indirect effect was significant for the social constructionist condition $\left(b=.09, S E_{\text {boot }}=.04,95 \%\right.$ CI $[.02, .18])$, but not for the biological condition $(b=-.003$, $S E_{\text {boot }}=.03,95 \%$ CI $\left.[-.06, .05]\right)$. In other words, exposure to social constructionist explanations of gender differences predicted a higher degree of discrimination attribution, and this effect was partially mediated by lowered endorsement of an essentialist gender lay theory. This means that partial support was found for Hypothesis 2 in that Hypothesis $2 \mathrm{~b}$ was supported but not Hypothesis 2a. See Table 5 for full model coefficients and Fig. 1 for a visualisation of the indirect effect of exposure to the social constructionist condition on discrimination attribution.

\section{Discussion}

The overall aim of the current study was to investigate if scientifically framed explanations of gender differences can influence individuals' gender lay theory. Furthermore, I
Table 3 Descriptive statistics by experimental condition for lay gender theory and discrimination attribution

\begin{tabular}{|c|c|c|c|c|c|c|c|c|}
\hline & \multicolumn{6}{|c|}{ Experimental Condition } & \multicolumn{2}{|l|}{ Total } \\
\hline & \multicolumn{2}{|c|}{ Biological } & \multicolumn{2}{|c|}{ Social-constructionist } & \multicolumn{2}{|c|}{ Control } & & \\
\hline & $M$ & $S D$ & $M$ & $S D$ & $M$ & $S D$ & $M$ & $S D$ \\
\hline Social gender theory & 3.38 & 1.12 & 3.76 & 1.20 & 3.15 & 1.18 & 3.41 & 1.19 \\
\hline Biological gender theory & 2.91 & 1.16 & 2.45 & .97 & 2.93 & 1.01 & 2.78 & 1.07 \\
\hline Gender theory, combined & 3.77 & 1.07 & 4.20 & .99 & 3.65 & .99 & 3.85 & 1.04 \\
\hline Discrimination attribution & 6.99 & 1.70 & 7.42 & 1.61 & 7.07 & 1.83 & 7.15 & 1.73 \\
\hline
\end{tabular}

Gender theory was measured on a 6-point scale on which higher numbers indicate greater endorsement of respective theory. The combined gender theory scale consists of a collapsed index of social and biological gender theory: lower values indicate a higher endorsement of an essentialist gender theory. Discrimination attribution was measured on a 9-point scale on which higher numbers indicate greater attribution of discrimination 
Table 4 Summary of hierarchical regression analysis for variables predicting gender lay theory

\begin{tabular}{|c|c|c|c|c|c|c|}
\hline \multirow[b]{2}{*}{ Predictors } & \multicolumn{2}{|l|}{ Step 1} & \multicolumn{2}{|l|}{ Step 2} & \multicolumn{2}{|l|}{ Step 3} \\
\hline & $\beta$ & $V I F$ & $\beta$ & $V I F$ & $\beta$ & $V I F$ \\
\hline Age & $-.10 *$ & 1.02 & $-.08 *$ & 1.08 & $-.09 *$ & 1.08 \\
\hline Modern sexism & $-.48 * * *$ & 1.52 & $-.46^{* * *}$ & 1.65 & $-.45 * * *$ & 1.74 \\
\hline Political orientation & $-.15 * * *$ & 1.31 & $-.14 * *$ & 1.32 & $-.15 * *$ & 1.33 \\
\hline Interest in gender issues & $.15^{* * *}$ & 1.33 & $.15^{* * *}$ & 1.35 & $.16^{* * *}$ & 1.36 \\
\hline Gender & & & -.05 & 1.20 & -.09 & 4.74 \\
\hline Biological condition & & & -.01 & 1.58 & -.002 & 2.22 \\
\hline Social Constructionist condition & & & $.16^{* * *}$ & 1.58 & $.13^{*}$ & 2.22 \\
\hline Gender*Biological & & & & & .01 & 8.00 \\
\hline Gender*Social Constructionist & & & & & .06 & 8.00 \\
\hline$d f$ & 364 & & 361 & & 359 & \\
\hline Adjusted $R^{2}$ & $.45^{* * *}$ & & .47 & & .47 & \\
\hline$\Delta R^{2}$ & & & $.02 * * *$ & & .001 & \\
\hline
\end{tabular}

$p<.05 . * * p<.01 . * * * p<.001$ investigated if these explanations influence discrimination attribution in response to a specific instance of gender discrimination. The gender lay theory manipulation was partially successful, with exposure to social constructionist explanations of gender differences leading to higher endorsement of a nonessentialist lay theory of gender compared to a no exposure control. However, exposure to biological explanations of gender differences did not lead to a difference in endorsed gender lay theory compared to a no exposure control.

There was no significant direct effect of exposure to scientific explanations of gender differences on discrimination attribution in the current study, but there was an indirect effect of exposure through gender lay theory. Exposure to social constructionist explanations of gender differences predicted higher endorsement of a non-essentialist gender lay theory, and endorsement of a less essentialist gender lay theory predicted a higher degree of discrimination attribution. There was no significant indirect effect of exposure to biological scientific explanations.

The current study found that there was no difference in gender lay theory between the control and the biological exposure conditions, which suggests that the biological explanations for gender differences included in the manipulated material are the ones most commonly endorsed by the general public in Sweden. This is in contrast with findings from Coleman and Hong (2008) who found that participants in the United States more strongly endorsed a social gender lay theory than a biological one following exposure to social explanations for gender differences, whereas exposure to biological explanations only lead to a small difference in

Table 5 Mediation analyses estimating the direct and indirect effects of experimental condition on discrimination attribution through gender lay theory

\begin{tabular}{|c|c|c|c|c|c|c|}
\hline \multirow[t]{2}{*}{ Predictor } & \multicolumn{3}{|c|}{ Gender lay theory } & \multicolumn{3}{|c|}{ Discrimination attribution } \\
\hline & $b(S E)$ & $95 \% \mathrm{CI}$ & $V I F$ & $b(S E)$ & $95 \% \mathrm{CI}$ & $V I F$ \\
\hline Age & $-.01(.004)^{*}$ & {$[-.010,-.001]$} & 1.04 & $.02(.01)^{* *}$ & {$[.01, .03]$} & 1.10 \\
\hline Modern sexism & $-.58(.06)^{* * *}$ & {$[-.70,-.46]$} & 1.65 & $-1.05(.12)^{* * *}$ & {$[-1.29,-.82]$} & 2.05 \\
\hline Political orientation & $-.10(.03)^{* *}$ & {$[-.16,-.04]$} & 1.32 & $.15(.06)^{* *}$ & {$[.04, .26]$} & 1.36 \\
\hline Interest in gender issues & $.14(.04)^{* * *}$ & {$[.06, .22]$} & 1.35 & $.02(.07)$ & {$[-.12, .17]$} & 1.39 \\
\hline Gender & $-.12(.10)$ & {$[-.31, .08]$} & 1.20 & $-.71(.18)$ & {$[-1.06,-.37]$} & 1.21 \\
\hline Biological condition & $-.01(.06)$ & {$[-.21, .19]$} & 1.16 & $-.003(.18)$ & {$[-.36, .35]$} & 1.21 \\
\hline Social constructionist condition & $.36(.10)^{* * *}$ & {$[.16, .56]$} & 1.16 & $.40(.19)^{*}$ & {$[.04, .77]$} & 1.21 \\
\hline Gender lay theory & & & & $.24(.09)^{*}$ & {$[.06, .42]$} & 1.91 \\
\hline \multirow[t]{2}{*}{ Constant } & $5.14(.29)^{* * *}$ & {$[4.58,5.71]$} & & $7.16(.69)^{* * *}$ & {$[5.80,8.53]$} & \\
\hline & \multicolumn{3}{|l|}{$R^{2}=.48$} & \multicolumn{2}{|l|}{$R^{2}=.42$} & \\
\hline
\end{tabular}

$* p<.05 . * * p<.01 . * * * p<.001$ 


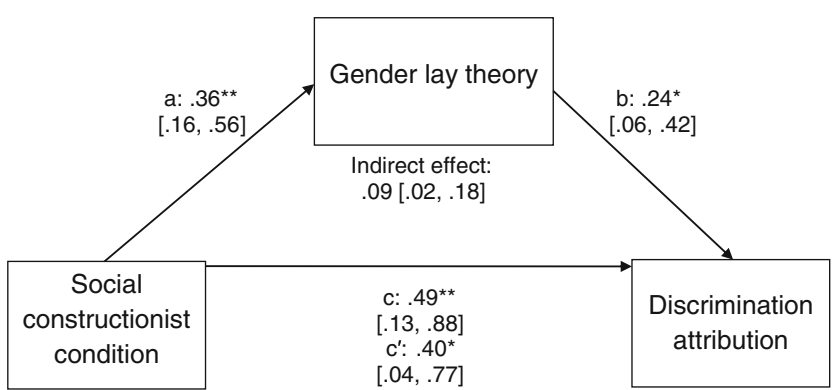

Fig. 1 Mediation model for the indirect effect of exposure to the social constructionist condition on discrimination attribution through gender lay theory. Coefficients are unstandardised and values in brackets are $95 \%$ confidence intervals. $* p<.05$. $* *<<.01$

gender lay theory endorsement. However, because Coleman and Hong did not include a control group that was not exposed to any explanations of gender differences, it is difficult to directly compare with the results of the current study. Related to effects of exposure to scientific explanations for gender differences on gender lay theory, Brescoll and LaFrance (2004) found that exposure to social explanations of gender differences increased participants' general belief that people are capable of change, whereas exposure to biological explanations lead to no difference compared to a control group. Although Brescoll and LaFrance did not measure specific gender lay theory, their results align with the findings of the current study to indicate that exposure to social explanations of gender differences specifically can affect individuals' reasoning about the mutability of characteristics.

Even though the effect of exposure to scientific material on gender lay theory was relatively small in the current study, it is nevertheless informative because it implies that even a short exposure to scientifically framed text regarding causes for gender differences can influence participants. This in turn supports the notion that everyday exposure to similar information can be expected to influence how individuals theorize regarding gender. In support of the effect of extensive exposure, attending a Psychology of Women course, for example, has been found to strongly increase students' endorsement of nonessentialist explanations of gender differences, even though these students started out with a higher degree of social constructionist thinking than students in other courses (Yoder et al. 2007). The current study thus provides further support to previous findings regarding the link between exposure to scientific explanations for gender differences and personal lay theories of gender (Brescoll and LaFrance 2004; Coleman and Hong 2008; Yoder et al. 2007) and provides the first known investigation into this relationship in a Swedish context.

That scientifically framed reasoning regarding gender and biology is used to legitimise gender stereotypes, especially those portraying men and women as complementary but equal (O'Connor and Joffe 2014), is a frequent criticism levelled at biologically focused studies of gender differences (Fine 2010; Meynell 2012). The results of the current study partially support this criticism by showing that exposure to biological explanations maintained a relatively high endorsement of an essentialist gender lay theory and that a higher endorsement of an essentialist gender lay theory predicted a lower degree of discrimination attribution. However, previous studies that have compared the effects of exposure to either biological or social explanations of gender differences on subsequent judgements have not definitively shown which type of explanation has an influence. For instance, Dar-Nimrod and colleagues (Dar-Nimrod et al. 2011) found that only social constructionist theories of gender differences had an impact on men's evaluation of sex crimes committed by other men, whereas evolutionary theories of gender difference had no effect. In contrast, Brescoll and LaFrance (2004) found that gender stereotype endorsement was heightened following exposure to biological explanations for gender differences compared to a control group, whereas exposure to social explanations had no effect. The current study found that only exposure to social constructionist explanations had any effect on discrimination attribution compared to the control group. This finding aligns with previous findings focused on the impact of gender essentialism on attributions regarding general discrimination, which show that exposure to social explanations for gender differences increases discrimination attribution whereas biological explanations have no effect (Cundiff and Vescio 2016). The current study allows those findings to be generalized from perception of group-based outcomes to perception of negative outcomes for a specific individual and implicates gender lay theory as the underlying mechanism behind the differing degrees of discrimination attribution.

Participants' gender was not a significant predictor for endorsement of gender lay theory or discrimination attribution, despite being significantly correlated with both gender lay theory and discrimination attribution. However, participants' gender also correlated with other background factors that were significant predictors of gender lay theory and/or discrimination attribution: specifically, modern sexism, political orientation, and general interest in gender issues. This suggests that the correlation of participants' gender with gender lay theory and discrimination attribution is due to differences among women and men in the sample regarding degree of modern sexism (lower for women), political orientation (more leftoriented for women), and general interest in gender issues (higher for women). This confounding effect of individual difference variables rather than gender itself may be a reason for previously reported inconsistent findings regarding the effect of participants' gender on the relation between exposure to scientific explanations for gender differences and gender lay theory (Morton et al. 2009; Kray et al. 2017). Using participants' gender as an analytical grouping should thus be done with care to avoid confounding the effect of gender category membership with that of other individual difference variables. This becomes especially important given the results 
from the current study, which show that even short-term exposure to scientifically framed reasoning regarding gender can have an impact on individuals' gender lay theories and that gender lay theories affect to what extent an instance of gender discrimination is recognised as such.

\section{Limitations and Future Research Directions}

Unlike material previously used for gender lay theory induction (Brescoll et al. 2013; Brescoll and LaFrance 2004), the material I used in the current study was not explicitly tested for credibility and believability. However, during the pilot testing of the manipulated texts there was no participant feedback indicating disbelief with the content of the articles, nor any feedback indicating that the material resulted in participants fatigue. The possibility of a difference in participants' acceptance of texts as excerpts from scientific articles is therefore seen as minimal. In order to ensure there are no systematic differences in participants' understanding or retention of the content of the manipulated texts, control questions could be included in future research studying the impact of scientific reporting. Even though the current study did not include such control questions, feedback was collected from colleagues during the creation of manipulated materials to ensure that the language difficulty of the two texts was similar.

Previous studies into the influence of gender lay theory on discrimination attribution has investigated the degree to which more general gender inequality is attributed to discriminatory practices (Cundiff and Vescio 2016; Morton et al. 2009). In an attempt to generalize these findings to have bearing on judgements of specific situations as discriminatory, the current study made use of vignettes describing specific instances of behaviour defined as discriminatory according to the Swedish Discrimination Act (Discrimination Act 2008:567) but displaying some ambiguity so that individual differences in perceptions could be captured. Although this was an important first step in investigating the influence of gender lay theory on evaluation of an actual discriminatory situation, future research should include a more systematic variation of potentially influential situational variables. This would allow for a continued study into how situational variables making gender more or less salient could potentially interact with gender lay theory with regard to discrimination attribution.

The current study made use of a sample that was recruited from various social media forums, with the aim of gathering a more general sample than the student sample primarily used in previous research. However, because demographic information about the sample is limited to age and gender, degree of sample representativeness is difficult to determine with regard to, for instance, geographical location, occupational status or ethnicity. Given that mine is the first known study into the topic of gender lay theory conducted in Sweden, it does however represent a first step toward gaining a clearer picture into how gender is conceptualised in a context which is considered to be gender equal (see for instance Towns 2002).

Evaluation of scientific findings has been shown to be affected by a preference for reductive explanations; for example, illogical explanations of phenomena are rated as more satisfactory when they contain biological information compared to when they do not (Hopkins et al. 2016; Weisberg et al. 2008). This preference for reductive explanations has been demonstrated in response to several sciences and is particularly strongly in regard to findings from the field of psychology paired with (non-explanatory) neuroscientific explanations (Hopkins et al. 2016). Furthermore, evaluation of the quality of scientific findings has also been found to be impacted by the extent to which the findings are favourable to evaluators' personal identity, an effect that was not mitigated by scientific training (Morton et al. 2006). Given the large amount of neuro-psychological research focused on finding neurological correlates for psychological gender differences (Rippon et al. 2014), as well as the widespread publicizing of these results (O'Connor and Joffe 2014), it would be fruitful to study how previous exposure to such reductive studies impacts gender lay theory and justification of the gender status quo.

It is important to note that although exposure to scientifically framed explanations for gender differences had a significant effect on gender lay theory and discrimination attribution, the effect was small compared to that of modern sexism. Endorsement of an essentialist gender lay theory and lower discrimination attribution was strongly predicted by a higher degree of modern sexism. That degree of modern sexism predicts discrimination attribution is not surprising given that one factor the scale was created to measure is "denial of continuing discrimination" (Swim et al. 1995, p. 200). However, the strong connection between gender lay theory and modern sexism is less obvious, and it supports the idea that gender essentialism is connected to justification of the current gender status quo. Reversing the direction of this relationship, a connection between estimates of the size of psychological gender differences and decreased ambivalent sexism has been found with exposure to scientific material that (correctly) reports gender differences as small (Zell et al. 2016). In the current study, degree of modern sexism did not differ between conditions, indicating that reading about essentialist or non-essentialist explanations for gender differences did not influence participants' degree of modern sexism. A possible reason for this discrepancy in results is that modern sexism has been found to be a subtler measure of sexism, whereas particularly the hostile sexism dimension of ambivalent sexism can be vulnerable to social desirability concerns (Swim et al. 2005). Continued research into the effects of exposure to scientific reasoning regarding gender and sexist attitudes could shed light on whether or not interventions focused on education to combat sexism can be effective or only influences expression of sexist attitudes rather than endorsement of them. 
A framework of analysis which has proved to be fruitful regarding social identity research is intersectional analysis (for a discussion on intersectionality as an analytical tool, see Lutz et al. 2011). There has been a multitude of calls for an increased focus on intersectional analysis in psychology (Cole 2009; Kang and Bodenhausen 2015; Keener 2015; Mehta 2015; Stewart and McDermott 2004). Although theories regarding how combinations of social positions interact has a long history (for a brief review, see Cole 2009), the term intersectionality was first introduced by Crenshaw (1989) in response to workplace discrimination against Black women in the United States. In this case, the legal division of gender or race as grounds for discrimination obscured the specific obstacles Black women faced as both women and Black, as well as specifically as Black women (Crenshaw 1989).

Cole (2009) suggests that intersectional questions can be addressed in psychological research through three important questions: Who is included in a social category, What role does inequality play, and Where are there similarities? Applying these questions to the current study reveals several areas in need of further study. Gender lay theory as an implicit person theory operates as an interpretative framework (Levy et al. 2001), which in its current operationalisation implies that individuals have a singular interpretative framework regarding gender. This is in contrast with research into intersectional stereotyping which shows that people have different stereotypes depending on how gender intersects with ethnicity (Ghavami and Peplau 2013) and sexual orientation (Blashill and Powlishta 2009; Ghavami and Peplau 2018). Furthermore, high-status subgroups have greater overlap with stereotypes regarding the general category of gender; for example, stereotypes about women in general are similar to those reported when asked about White, heterosexual women specifically but different from those reported about women who are Black (Ghavami and Peplau 2013) or lesbian (Ghavami and Peplau 2018).

In the current study, I attempted to investigate gender lay theory in isolation from other social categorisations, but this, in all probability, does mean that the results mainly apply to perceptions of heterosexual Swedish ethnic majority members. Further studies focusing on how lay theories regarding social categories relate to intersecting identities are needed to determine how individuals' conceptualisation of gender is influenced by the impossibility of isolating gender from other social categories. The role of inequality in regard to gender essentialism is a question of key importance because gender essentialism can be strategically invoked to protect the interests of a higher-status group (Morton et al. 2009). This makes issue of how an individual's own social status in relation to that of the group in focus influences how categories are conceptualised and is an area of specific need for further research.

\section{Practice Implications}

The current study showed that exposure to social constructionist explanations for gender differences can decrease individuals' endorsement of an essentialist gender lay theory and that a less essentialist conceptualisation of gender as a social category increases the extent to which instances of genderbased unfair treatment is recognised as discrimination. This has practical implications for efforts aimed at decreasing gender discrimination because it opens up the possibility of using education campaigns focused on describing social constructionist theories of gender to assist in decreasing the number of unreported cases of gender discrimination in the workplace.

\section{Conclusion}

The current study demonstrated that a scientifically framed explanation for gender differences could alter the way that individuals conceptualise gender and that an individual's gender lay theory can influence the extent to which discrimination is recognised as such. These findings support a conclusion that scientifically framed descriptions of women and men as natural and entitative groups can contribute to gender inequality by leaving a biased status quo intact. This should give further incentive for scientists to continue to strive for a nuanced reporting of findings related to gender differences and to aim for a high degree of reflexivity.

Acknowledgements I would like to thank Anna Lindqvist for guidance in conducting this research as well as invaluable comments on manuscript drafts.

\section{Compliance with Ethical Standards}

Disclosure of Potential Conflicts of Interest The author received no financial support for the research, authorship, and/or publication of this article. The author has no conflicts of interests to declare.

Research Involving Human Participants and/or Animals This study involved human participants and was conducted in accordance with ethical standards set forth by the American Psychological Association and the Swedish Research Council.

Informed Consent Informed consent was obtained from all individual participants included in the study and all participants were debriefed following completion of the study.

Open Access This article is distributed under the terms of the Creative Commons Attribution 4.0 International License (http:// creativecommons.org/licenses/by/4.0/), which permits unrestricted use, distribution, and reproduction in any medium, provided you give appropriate credit to the original author(s) and the source, provide a link to the Creative Commons license, and indicate if changes were made. 


\section{References}

Andreychik, M. R., \& Gill, M. J. (2015). Do natural-kind beliefs about social groups contribute to prejudice? Distinguishing bio-somatic essentialism from bio-behavioral essentialism, and both of these from entitativity. Group Processes \& Intergroup Relations, 18(4), 454-474. https://doi.org/10.1177/1368430214550341.

Ansara, Y. G., \& Hegarty, P. (2014). Methodologies of misgendering: Recommendations for reducing cisgenderism in psychological research. Feminism \& Psychology, 24(2), 259-270. https://doi.org/10. 1177/0959353514526217.

Bastian, B., \& Haslam, N. (2008). Immigration from the perspective of hosts and immigrants: Roles of psychological essentialism and social identity. Asian Journal of Social Psychology, 11(2), 127-140. https://doi.org/10.1111/j.1467-839X.2008.00250.x.

Blackless, M., Charuvastra, A., Derryck, A., Fausto-Sterling, A., Lauzanne, K., \& Lee, E. (2000). How sexually dimorphic are we? Review and synthesis. American Journal of Human Biology, 12(2), 151-166. https://doi.org/10.1002/(SICI)1520-6300(200003/04)12: $2<151::$ AID-AJHB1>3.0.CO;2-F.

Blashill, A. J., \& Powlishta, K. K. (2009). Gay stereotypes: The use of sexual orientation as a cue for gender-related attributes. Sex Roles, 61(11-12), 783-793. https://doi.org/10.1007/s11199-009-9684-7.

Brescoll, V., \& LaFrance, M. (2004). The correlates and consequences of newspaper reports of research on sex differences. Psychological Science, 15(8), 515-520. https://doi.org/10.1111/j.0956-7976.2004. 00712.x.

Brescoll, V. L., Uhlmann, E. L., \& Newman, G. E. (2013). The effects of system-justifying motives on endorsement of essentialist explanations for gender differences. Journal of Personality and Social Psychology, 105(6), 891-908. https://doi.org/10.1037/a0034701.

Buss, D. M. (1995). Psychological sex differences: Origins through sexual selection. American Psychologist, 50(3), 164-168. https://doi. org/10.1037/0003-066X.50.3.164.

Butler, J. (2006). Gender trouble: Feminism and the subversion of identity (p. 2006). London: Routledge.

Cole, E. R. (2009). Intersectionality and research in psychology. American Psychologist, 64(3), 170-180. https://doi.org/10.1037/a0014564.

Coleman, J. M., \& Hong, Y.-Y. (2008). Beyond nature and nurture: The influence of lay gender theories on self-stereotyping. Self and Identity, 7(1), 34-53. https://doi.org/10.1080/15298860600980185.

Connell, R. (1987). Gender and power: Society, the person and sexual politics. Cambridge: Polity (in association with Blackwell, 1987).

Connell, R. (1995). Masculinities. Berkeley: University of California Press.

Crenshaw, K. (1989). Demarginalizing the intersection of race and sex: A Black feminist critique of antidiscrimination doctrine, feminist theory and antiracist politics. University of Chicago Legal Forum, 1989(1), 139-167.

Cundiff, J. L., \& Vescio, T. K. (2016). Gender stereotypes influence how people explain gender disparities in the workplace. Sex Roles, 75(34), 126-138. https://doi.org/10.1007/s11199-016-0593-2.

Dar-Nimrod, I., Heine, S. J., Cheung, B. Y., \& Schaller, M. (2011). Do scientific theories affect men's evaluations of sex crimes? Aggressive Behavior, 37(5), 440-449. https://doi.org/10.1002/ab.20401.

Discrimination Act. (2008:567). Retrieved from http://www.riksdagen. se/sv/dokument-lagar/dokument/svensk-forfattningssamling/ diskrimineringslag-2008567 sfs-2008-567

Dweck, C. S., Chiu, C. Y., \& Hong, Y. Y. (1995). Implicit theories and their role in judgments and reactions: A world from two perspectives. Psychological Inquiry, 6(4), 267-285. https://doi.org/10.1207/ s15327965pli0604_1.

Ekehammar, B., Akrami, N., \& Araya, T. (2000). Development and validation of Swedish classical and modern sexism scales.
Scandinavian Journal of Psychology, 41(4), 307-314. https://doi. org/10.1111/1467-9450.00203.

Fine, C. (2010). Delusions of gender: How our minds, society, and neurosexism create difference. New York: W.W. Norton.

Gaertner, S. L., \& Dovidio, J. F. (2005). Understanding and addressing contemporary racism: From aversive racism to the common ingroup identity model. Journal of Social Issues, 61(3), 615-639. https://doi. org/10.1111/j.1540-4560.2005.00424.x.

Gelman, S. A., Collman, P., \& Maccoby, E. E. (1986). Inferring properties from categories versus inferring categories from properties: The case of gender. Child Development, 57(2), 396-404. https://doi.org/10. 2307/1130595.

Ghavami, N., \& Peplau, L. A. (2013). An intersectional analysis of gender and ethnic stereotypes: Testing three hypotheses. Psychology of Women Quarterly, 37(1), 113-127. https://doi.org/10.1177/ 0361684312464203 .

Ghavami, N., \& Peplau, L. A. (2018). Urban middle school students' stereotypes at the intersection of sexual orientation, ethnicity, and gender. Child Development, 89(3), 881-896. https://doi.org/10. 1111/cdev.12763.

Gustafsson Sendén, M., Bäck, E. A., \& Lindqvist, A. (2015). Introducing a gender-neutral pronoun in a natural gender language: The influence of time on attitudes and behavior. Frontiers in Psychology, 6(July), 1-12. https://doi.org/10.3389/fpsyg.2015.00893.

Haslam, N., Rothschild, L., \& Ernst, D. (2000). Essentialist beliefs about social categories. British Journal of Social Psychology, 39, 113127. https://doi.org/10.1348/014466600164363.

Hayes, A. F. (2013). Introduction to mediation, moderation, and conditional process analysis: A regression-based approach (p. 2013). New York: Guilford.

Hegarty, P., Ansara, Y., \& Barker, M. (2018). Nonbinary gender identities. In N. K. Dess, J. Marecek, \& L. C. Bell (Eds.), Gender, sex, and sexualities: Psychological perspectives (pp. 53-76). New York: Oxford University Press.

Hong, Y., Coleman, J., Chan, G., Wong, R. Y. M., Chiu, C., Hansen, I. G., ... Fu, H. (2004). Predicting intergroup bias: The interactive effects of implicit theory and social identity. Personality and Social Psychology Bulletin, 30(8), 1035-1047. https://doi.org/10.1177/ 0146167204264791

Hopkins, E. J., Weisberg, D. S., \& Taylor, J. C. V. (2016). The seductive allure is a reductive allure: People prefer scientific explanations that contain logically irrelevant reductive information. Cognition, 155, 67-76. https://doi.org/10.1016/j.cognition.2016.06.011.

Hyde, J. S., Bigler, R. S., Joel, D., Tate, C. C., \& van Anders, S. M. (2018). The future of sex and gender in psychology: Five challenges to the gender binary. American Psychologist, 74(2), 171-193. https://doi.org/10.1037/amp0000307.

Jost, J. T., Banaji, M. R., \& Nosek, B. A. (2004). A decade of system justification theory: Accumulated evidence of conscious and unconscious bolstering of the status quo. Political Psychology, 25(6), 881919. https://doi.org/10.1111/j.1467-9221.2004.00402.x.

Kaiser, C. R., Dyrenforth, P. S., \& Hagiwara, N. (2006). Why are attributions to discrimination interpersonally costly? A test of systemand group-justifying motivations. Personality and Social Psychology Bulletin, 32(11), 1523-1536. https://doi.org/10.1177/ 0146167206291475 .

Kang, S. K., \& Bodenhausen, G. V. (2015). Multiple identities in social perception and interaction: Challenges and opportunities. Annual Review of Psychology, 66, 547-574. https://doi.org/10.1146/ annurev-psych-010814-015025.

Kay, A. C., Jost, J. T., Mandisodza, A. N., Sherman, S. J., Petrocelli, J. V., \& Johnson, A. L. (2007). Panglossian ideology in the service of system justification: How complementary stereotypes help us to rationalize inequality. In M. P. Zanna (Ed.), Advances in experimental social psychology (Vol. 39, pp. 305-358). San Diego: Elsevier. https://doi.org/10.1016/S0065-2601(06)39006-5. 
Keener, E. (2015). The complexity of gender: It is all that and more... In sum, it is complicated. Sex Roles, 73(11-12), 481-489. https://doi. org/10.1007/s11199-015-0542-5.

Keller, J. (2005). In genes we trust: The biological component of psychological essentialism and its relationship to mechanisms of motivated social cognition. Journal of Personality and Social Psychology, 88(4), 686-702. https://doi.org/10.1037/0022-3514.88.4.686.

Kray, L. J., Howland, L., Russell, A. G., \& Jackman, L. M. (2017). The effects of implicit gender role theories on gender system justification: Fixed beliefs strengthen masculinity to preserve the status quo. Journal of Personality and Social Psychology, 112(1), 98-115. https://doi.org/10.1037/pspp0000124.

Levy, S. R., Plaks, J. E., Hong, Y., Chiu, C., \& Dweck, C. S. (2001). Static versus dynamic theories and the perception of groups: Different routes to different destinations. Personality and Social Psychology Review, 5(2), 156-168. https://doi.org/10.1207/S15327957PSPR0502 6.

Lindqvist, A., Gustafsson Sendén, M., \& Bäck, E. A. (2016). Vem tycker om hen? [Who likes hen?]. Språk och stil, 26, 101-129.

Lutz, H., Herrera Vivar, M. T., \& Supik, L. (2011). Framing intersectionality. [Electronic resource]: debates on a multi-faceted concept in gender studies (p. 2011). Farnham: Ashgate.

Major, B., Quinton, W. J., \& McCoy, S. K. (2002). Antecedents and consequences of attributions to discrimination: Theoretical and empirical advances. Advances in Experimental Social Psychology, 34, 251-330. https://doi.org/10.1016/S0065-2601(02)80007-7.

Martin, C. L., \& Parker, S. (1995). Folk theories about sex and race differences. Personality and Social Psychology Bulletin, 21(1), 45-57. https://doi.org/10.1177/0146167295211006.

Medin, D., \& Ortony, A. (1989). Psychological essentialism. In S. Vosniadou \& A. Ortony (Eds.), Similarity and analogical reasoning (pp. 179-196). Cambridge: Cambridge University Press. https://doi. org/10.1017/CBO9780511529863.009.

Mehta, C. M. (2015). Gender in context: Considering variability in Wood and Eagly's traditions of gender identity. Sex Roles, 73(11-12), 490 496. https://doi.org/10.1007/s11199-015-0535-4.

Meynell, L. (2012). Evolutionary psychology, ethology, and essentialism (because what they don't know can hurt us). Hypatia, 27(1), 3-27. https://doi.org/10.1111/j.1527-2001.2011.01240.x.

Morgan, E. M., \& Davis-Delano, L. R. (2016). How public displays of heterosexual identity reflect and reinforce gender stereotypes, gender differences, and gender inequality. Sex Roles, 75(5-6), 257-271. https://doi.org/10.1007/s11199-016-0613-2.

Morton, T. A., Haslam, S. A., Postmes, T., \& Ryan, M. K. (2006). We value what values us: The appeal of identity-affirming science. Political Psychology, 27(6), 823-838. https://doi.org/10.1111/j. 1467-9221.2006.00539.x.

Morton, T. A., Postmes, T., Haslam, S. A., \& Hornsey, M. J. (2009). Theorizing gender in the face of social change: Is there anything essential about essentialism? Journal of Personality and Social Psychology, 96(3), 653-664. https://doi.org/10.1037/a0012966.

O'Connor, C., \& Joffe, H. (2014). Gender on the brain: A case study of science communication in the new media environment. PLOS ONE, 9(10), 1-15. https://doi.org/10.1371/journal.pone.0110830.

Plaks, J. E. (2017). Implicit theories: Assumptions that shape social and moral cognition. In J. M. Olson (Ed.), Advances in experimental social psychology (Vol. 56, pp. 259-310). New York: Academic Press. https://doi.org/10.1016/bs.aesp.2017.02.003.

Racine, E., Bar-Ilan, O., \& Illes, J. (2005). fMRI in the public eye. Nature Reviews. Neuroscience, 6(2), 159-164. https://doi.org/10.1038/ nrn1609.

Rangel, U., \& Keller, J. (2011). Essentialism goes social: Belief in social determinism as a component of psychological essentialism. Journal of Personality and Social Psychology, 100(6), 1056-1078. https:// doi.org/10.1037/a0022401.

Rippon, G., Jordan-Young, R., Kaiser, A., \& Fine, C. (2014). Recommendations for sex/gender neuroimaging research: Key principles and implications for research design, analysis, and interpretation. Frontiers in Human Neuroscience, 8(August), 1-13. https://doi.org/10.3389/fnhum.2014.00650.

Rothbart, M., \& Taylor, M. (1992). Category labels and social reality: Do we view social categories as natural kinds? In G. R. Semin \& K. Fiedler (Eds.), Language, interaction and social cognition (pp. 1136). London: Sage.

Snyder, M. (1983). The influence of individuals on situations: Implications for understanding the links between personality and social behavior. Journal of Personality, 51(3), 497-516. https:// doi.org/10.1111/j.1467-6494.1983.tb00342.x.

Stewart, A. J., \& McDermott, C. (2004). Gender in psychology. Annual Review of Psychology, 55, 519-544. https://doi.org/10.1146/ annurev.psych.55.090902.141537.

Stone, A. (2004). Essentialism and anti-essentialism in feminist philosophy. Journal of Moral Philosophy, 1(2), 135-153. https://doi.org/10. 1177/174046810400100202.

Swedish Research Council. (2017). Good research practice. Retrieved from ht t p s : / / w w w. vr.se/down load/18. 5639980c162791bbfe697882/1529480529472/Good-ResearchPractice VR 2017.pdf.

Swim, J. K., Aikin, K. J., Hall, W. S., \& Hunter, B. A. (1995). Sexism and racism: Old-fashioned and modern prejudices. Journal of Personality and Social Psychology, 68(2), 199-214. https://doi. org/10.1037/0022-3514.68.2.199.

Swim, J. K., Mallett, R., Russo-Devosa, Y., \& Stangor, C. (2005). Judgments of sexism: A comparison of the subtlety of sexism measures and sources of variability in judgments of sexism. Psychology of Women Quarterly, 29(4), 406-411. https://doi.org/10.1111/j. 1471-6402.2005.00240.x.

Towns, A. (2002). Paradoxes of (in)equality: Something is rotten in the gender equal state of Sweden. Cooperation and Conflict, 37(2), 157-179. https://doi.org/10.1177/0010836702037002975.

Weisberg, D. S., Keil, F. C., Goodstein, J., Rawson, E., \& Gray, J. R. (2008). The seductive allure of neuroscience explanations. Journal of Cognitive Neuroscience, 20(3), 470-477. https://doi.org/10.1162/jocn.2008.20040.

Wood, W., \& Eagly, A. H. (2012). Biosocial construction of sex differences and similarities in behavior. Advances in Experimental Social Psychology, 46, 55-123. https://doi.org/10.1016/B978-0-12394281-4.00002-7.

World Economic Forum. (2018). Global Gender Gap Report. Retrieved from http://www3.weforum.org/docs/WEF_GGGR 2018.pdf

Yoder, J. D., Fischer, A. R., Kahn, A. S., \& Groden, J. (2007). Changes in students' explanations for gender differences after taking a psychology of women class: More constructionist and less essentialist. Psychology of Women Quarterly, 31(4), 415-425. https://doi.org/ 10.1111/j.1471-6402.2007.00390.x.

Yzerbyt, Vincent, Y., Rogier, A., Fiske, \& Susan, T. (1998). Group entitativity and social attribution: On translating situational constraints into stereotypes. Personality and Social Psychology Bulletin, 24(10), 1089-1103. https://doi.org/10.1177/01461672982410006.

Yzerbyt, V., Corneille, O., \& Estrada, C. (2001). The interplay of subjective essentialism and entitativity in the formation of stereotypes. Personality and Social Psychology Review, 5(2), 141-155. https:// doi.org/10.1207/s15327957pspr0502_5.

Zell, E., Strickhouser, J. E., Lane, T. N., \& Teeter, S. R. (2016). Mars, Venus, or Earth? Sexism and the exaggeration of psychological gender differences. Sex Roles, 75(7-8), 287-300. https://doi.org/10. 1007/s11199-016-0622-1.

Publisher's Note Springer Nature remains neutral with regard to jurisdictional claims in published maps and institutional affiliations. 